\title{
Social Determinants and Ethnic Factors Associated with a New Spatial Distribution of Maternal Mortality for a City of Colombia (2000-2019)
}

\author{
Julián A. Peláez Freire, Mauricio Hernández-Carrillo, Liliana Arias Castillo, \\ Jorge A. Holguin Ruiz, and Julián A Herrera Murgueitio
}

\section{ABSTRACT}

Introduction: Maternal mortality in our region observed a significative reduction, however, it continues to be a public health problem. In CaliColombia was traditionally concentrated in the eastern and hillside areas and with high prevalence of afroamerican patients.

Materials and methods: To analyze the behavior of maternal mortality during the last twenty years in the city, an ecological analytical study of spatial correlation was carried out including in the analysis, economic, sociocultural and health care factors. Univariate, bivariate and multivariate analyzes were performed.

Results: The spatial analysis showed clusters of maternal mortality in the northern and central areas of the city. As a risk factor for maternal mortality, it was observed that in pregnant women belonging to the mixed ethnic backgrounds and spanic white ethnicity from low socioeconomic income (IRR: 1.13, 95\% CI 1.03-1.24). Access to basic education (OR: 0.66, 95\% CI 0.53-0.83), attendance at prenatal care (OR: 0.95 95\% CI 0.93-0.98) and access to health institutions (OR: $0.96,95 \%$ CI: $0.95-0-97)$ identified as protective factors for maternal mortality.

Conclusion: The clusters for maternal-perinatal mortality in the city during the last two decades had a significant spatial change with a new pattern of risk factors associated to maternal mortality.

Keywords: ecological study, economic, geographic information system, health care Maternal mortality, spatial analysis, sociocultural factors.

Submitted : June 04, 2021

Published : July 04, 2021

ISSN: 2593-8339

DOI: $10.24018 /$ ejmed.2021.3.4.916

Julian A. Pelaez Freire

Epidemiologist, Valle Departmental Health Secretariat, Colombia.

(e-mail: julian.pelaez@ gmail.com)

Mauricio Hernandez Carrillo

Assistant Professor, Faculty of Health, Universidad del Valle, Professor at the National Sports School, Researcher Municipal Health Secretariat of Cali, Colombia.

(e-mail: mauriciohc@gmail.com)

Liliana Arias Castillo

Distinguished Full Professor, Department of Family Medicine, Academic Vice Chancellor Universidad del Valle, Colombia.

(e-mail:

liliana.arias.castillo@correounivalle.edu.co.) Jorge A. Holguin Ruiz

Epidemiologist, Municipal Health Secretariat of Cali, Adjunct professor, Pontifical Javeriana University of Cali, Colombia.

(e-mail: jholguinr@javerianacali.edu.co) Julián A. Herrera Murgueitio*

Emeritus and Honorary Professor of Medicine, Department of Family Medicine Universidad del Valle, Colombia.

(e-mail:

julian.herrera@correounivalle.edu.co

*Corresponding Author

local and documented by their respective Clinical History in the city of Cali-Colombia, in the period between 2000-2019.

\section{INTRODUCTION}

Maternal mortality (MM) is a public health problem that mainly affects developing countries with a family, social and economic impact [1]. Official reports on the behavior of maternal mortality at the level of Cali and the Department of Valle del Cauca, report the behavior of the MM georeferenced by commune without having described the pattern of geographic distribution associated with economic variables and social determinants [2]. The National Health Observatory has required more specific local analyzes on the behavior of maternal mortality. In response to this call, this research evaluated economic, sociocultural and health care factors that could be associated with MM describing the clusters for maternal deaths that had been analyzed by the Maternal Mortality Surveillance Committee (MMSC)

\section{MATERIALS AND METHODS}

An ecological study was carried out by multiple groups with an analytical approach, studying groups by geographic areas and time periods. The study population was made up of pregnant women who died during their pregnancy, childbirth, and puerperium in the period 2000 to 2019 in the city of Cali-Colombia. The study was approved by the Institutional Ethics Committee of the Faculty of Health of the Universidad del Valle. The variable resulting from the study was the Maternal Mortality Ratio (MMR), defined as the number of deaths in pregnancy, childbirth and the puerperium that occurred in one year divided by the total 
number of live births presented, the above expressed per 100,000 live births. The independent variables were economic sociocultural, and health case factors, related to medical care and those related to the gestation process. The ecological variables were obtained from public databases by commune of the city of Cali - Colombia from sources of the National, Departmental, Municipal Government and the CIDSE economics research group of the Universidad del Valle in the city.

\section{ANALYSIS OF DATA}

A descriptive analysis was carried out for the quantitative variables, the measures of central tendency and dispersion were obtained, for the qualitative variables the frequency charts were documented. A bivariate analysis was performed comparing the independent variables and the dependent variable maternal mortality Ratio. For the ecological variables, a multivariate analysis was carried out, the data distribution was elaborated to adjust the analysis, through the validation of assumptions, we proceeded to investigate which distribution was adjusted. Binomial regression [3] was carried out in which the dependent variable [IRR (Incident Rate Ratio)] was modeled, since it was a study in which the follow-up time was taken into account. This model was adjusted to our study, the assumptions of overdispersion were verified allowing greater flexibility of the variance, which does not occur in the Poisson regression [4]. For the spatial analysis, the Arcgis v13.2.1 analysis program was used together with the Geoda v1 8 software, since they provided the location of the data by commune and residence address on the map of Cali, as well as punctually identifying the events that occurred in the years 2000-2019 and the behavior of maternal mortality was described through point-polygon analysis clusters. The maternal mortality ratio was evaluated in relation to the affectation that could occur due to the presence or absence of a second or third exposure, allowing to identify in which variable should be intervened and the pertinent actions in public health.

\section{Results}

The economic, sociocultural and health care factors in relation to maternal mortality in Cali-Colombia from 2000 to 2019 are described in Table I. Three houndred and thirty threee maternal deaths were recorded, which were georeferenced and adjusted to describe the risk clusters in the municipality of Cali-Colombia. The communes with maternal mortality are presented according to the residence of the pregnant woman during the study period (2000-2019) (Fig. 1). The MMR by year indicated that there was no spatial dependence in the distribution of maternal deaths (Fig. 2). During the study period (2000-2019) the Moran Index observed that there was a concentration in maternal mortality in central and eastern areas, with a positive spatial correlation of high-high and high-low $\left(r^{2}=0.06\right)$ and for the year $2005\left(r^{2}=0.14, p<0.05\right)$ (Fig. 3).

The maternal mortality ratio has had important variations over the years, with peaks in the years 2009, 2012, 2014,
2017, 2018, the highest risk for maternal mortality was presented in commune 3 , followed by commune 18 ; The variability of the risk of maternal mortality by commune was evaluated with the coefficient of variation, observing that the commune with the most variability is number 22 (coefficient of variation of 127\%) and the commune with the least variability was commune 18 with $43 \%$ (Fig. 1). For the final statistical modeling, it was used as a criterion to include the variables in the model, according to the parsimony principle, which allows explaining an event with the fewest possible variables, performing a negative binomial regression based on the observed probability distribution, taking into account only the covariates with a significance level of 0.25 proposed by Hosmer \& Lemeshow [3].

In the preliminary statistical model, it was observed that the number of homicides due to traffic accidents, the number of secondary educational institutions were not associated with the maternal mortality ratio (Table I). A weak association was observed between having a job in the pregnant woman, number of second basic education institutions, homicides from traffic accidents, afrodescendant ethnicity, child mortality, number of health institutions (Table I). A weak effect of interaction between stratum with sociodemographic and economic characteristics (Table II). As a risk factor for maternal mortality, it was observed that in pregnant women belonging to the mixed ethnic backgrounds and spanic white ethnicity from low socioeconomic income (IRR: 1.13, 95\% CI 1.03-1.24). Access to basic education (OR: $0.66,95 \%$ CI 0.53-0.83), attendance at prenatal care (OR: $0.9595 \% \mathrm{CI}$ 0.93-0.98) and access to health institutions (OR: 0.96, 95\% CI: 0.95-0-97) identified as protective factors for maternal mortality.

TABLE I: ECONOMIC, SOCIOCULTURAL AND HEALTH CARE FACTORS Evaluated in RElation to Maternal MoRtality. CALI-COLOMBia (2000-2019)

\begin{tabular}{ccc}
\hline Factors & Maternal mortality ratio & IRR $(95 \%$ CI $)$ \\
\hline Economic & Work & $0.99(0.99-1.00)$ \\
Sociocultural & Number of secondary basic & $0.98(0.98-0.99)$ \\
& educational institutions & \\
& Homicides from traffic accidents & $1.01(1.00-1.02)$ \\
& Afro-descendant ethnicity & $0.96(0.93-1.00)$ \\
Health care & Child mortality & $0.95(0.95-0.95)$ \\
& Number of health institutions & $0.96(0.95-0.97)$ \\
\hline
\end{tabular}

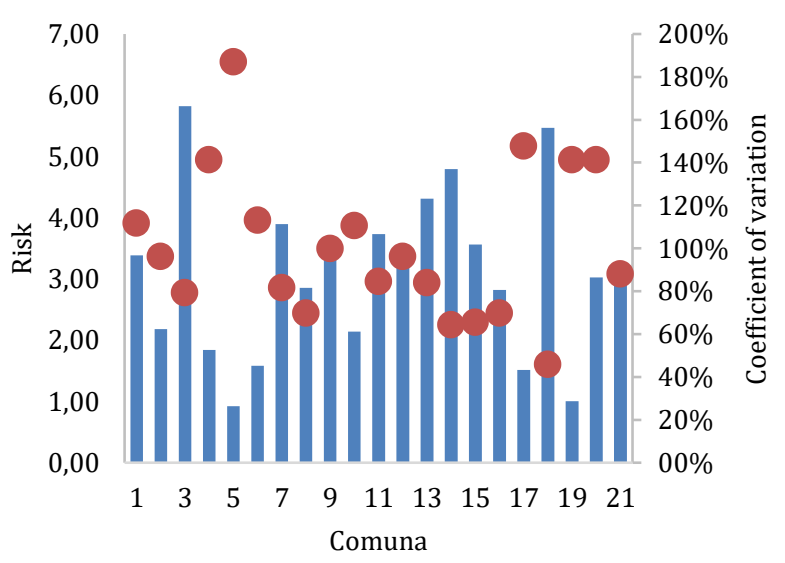

Fig. 1. Maternal mortality by commune. Cali-colombia. 2000-2019. 
TABLE II: EFFECTS OF INTERACTION. ECONOMIC, SOCIO-CULTURAL FACTORS AND Health CARE. Maternal Mortality. CAli-COlOMBia,

\begin{tabular}{|c|c|c|c|c|}
\hline Maternal mortality ratio & IRR & $\mathrm{p}$ value & $\begin{array}{c}\mathrm{CI} \\
{[95 \% \mathrm{CI}]}\end{array}$ & \\
\hline Stratum according with have job & 0.99 & $<0.01$ & 0.99 & 0.99 \\
\hline $\begin{array}{l}\text { Stratum according to number of } \\
\text { primary basic educational } \\
\text { institutions }\end{array}$ & 1.00 & $<0.01$ & 1.00 & 1.00 \\
\hline $\begin{array}{c}\text { Stratum according to number of } \\
\text { secondary basic educational } \\
\text { institutions }\end{array}$ & 1.00 & $<0.01$ & 1.00 & 1.00 \\
\hline $\begin{array}{l}\text { Stratum according to number of } \\
\text { homicides due to traffic accidents }\end{array}$ & 0.99 & $<0.01$ & 0.99 & 0.99 \\
\hline $\begin{array}{l}\text { Stratum according to Afro- } \\
\text { descendant }\end{array}$ & 0.99 & $<001$ & 0.99 & 0.99 \\
\hline $\begin{array}{l}\text { Stratum according to mestizo / } \\
\text { white }\end{array}$ & 1.13 & $<0.01$ & 1.03 & 1.24 \\
\hline $\begin{array}{l}\text { Stratum according to infant } \\
\text { mortality rate }\end{array}$ & 1.00 & $<0.01$ & 1.00 & 1.00 \\
\hline $\begin{array}{l}\text { Stratum according to infant } \\
\text { mortality }\end{array}$ & 0.99 & $<0.01$ & 0.99 & 0.99 \\
\hline $\begin{array}{l}\text { Stratum according to prenatal } \\
\text { control }\end{array}$ & 0.98 & $<001$ & 0.98 & 0.99 \\
\hline
\end{tabular}

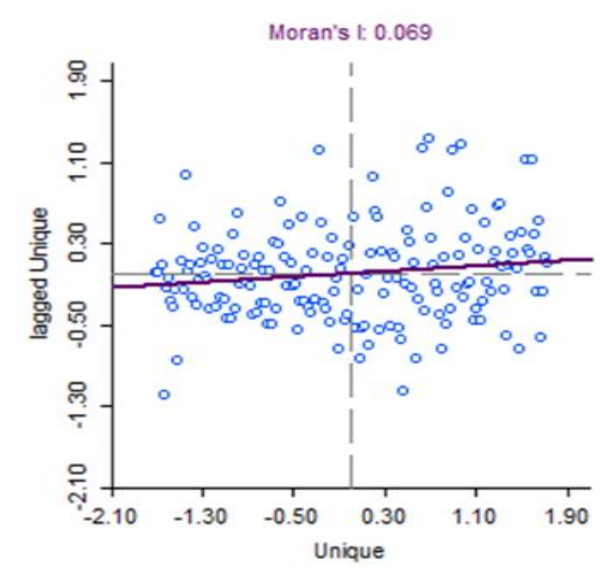

Fig. 2. Maternal mortality Moran's index. Cali-Colombia. 2000-2019.

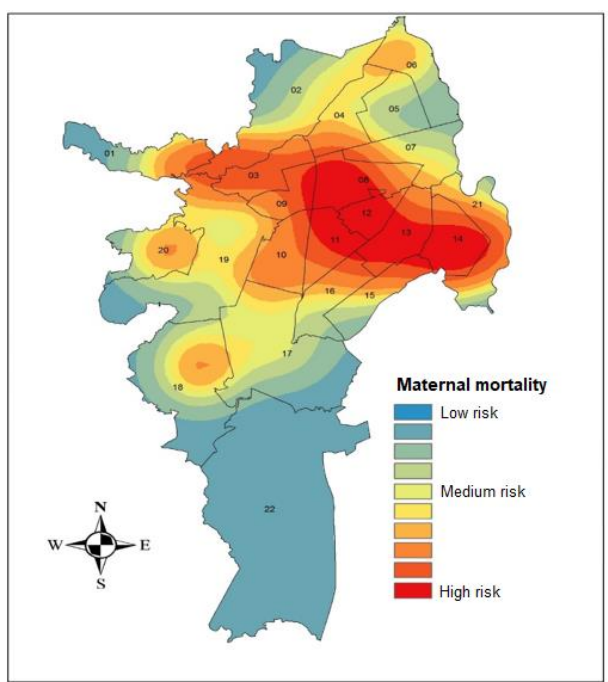

Fig. 3. Risk areas of maternal mortality. Cali-Colombia. 2000-2019.

\section{DISCUSSION}

Maternal mortality in the city of Cali during the study period was more accentuated in any communes (Fig. 1) where there are structural social problems and migratory states due to forced displacement (rural to urban areas), increasing rates of violence, accidents, and injuries. Maternal deaths are multifactorial and in a large proportion preventable and associated in a large proportion with problems in the social structure, as was observed in the study by Hazarika L \& Pukan P [1], where it was identified that follow-up was important for the prevention of maternal deaths of pregnancy at the community or institutional level, promoting prenatal visits, limiting the practices of irrational cultural beliefs, and reducing inequities.

The policy on sexual and reproductive health improved .00 the quality of data in vital statistics [SIVIGILA and vital records of the National Administrative Department of

0.99 Statistics (DANE)], in addition to resolution 412, agreement 117 and the Resolution 3384 of 2000 of the National Council of Social Security, sensitized and stimulated the .24 training of maternal and child health teams in the country, guaranteeing that the health institutions had a better action

00 in the care of pregnant women [5]-[8] this led to a reduction 99 in maternal deaths in the country. For the reduction of maternal mortality, greater achievements were observed at 99 the local and national levels, improving the articulation between surveillance and risk intervention at the prenatal level. The socioeconomic variables evaluated in this study coincides with the results of previous research; women head of households have a lower risk of presenting a maternal death when their social support is improved [6]-[8]. The lack of social support improves inflammatory response and preeclampsia [9] the first cause of maternal mortality in developing countries.

The relationship studied at the commune level had a similar reflection in those years, which indicated that the decrease in maternal deaths may be very closely related to some socio-economic and cultural variables that were found significantly in the present study. Liese-KB \& Maeder A [7] affirm in the same way that the analysis of social factors represents an impact on the lives of women, despite not having a direct relationship with the physiology of pregnancy, its indirect effect on maternal mortality is preventive. Cárdenas-Cárdenas L. M. \& Cotes-Cantillo K. [10] carried out a study of similar characteristics, ecological type, but at the municipal and departmental level throughout Colombia. The authors concluded that the maternal mortality ratio was associated with social and economic variables. The results of this study showed that the number of basic educational institutions is a protective factor, it was not observed that the secondary school supply was associated with MMR, supported by the fact that illiteracy increases the risk of MMR [6]-[8]. In relation to the cases georeferenced by commune of residence, we could observe that the social determinants of health are fundamental in terms of the impact on the well-being and environment of women. This impact could be evidenced with the work carried out in the ASIS 2014 (Colombia, Maternal Mortality of the year 2011) [11] where inequality was marked in the low socio-economic strata.

Pina et al [12] developed an ecological study where they evaluated the ratio of maternal mortality versus variables of place of birth and prenatal control. In this study, they concluded that to reduce the risks in pregnant women and births, policies and access to health systems must be improved. Intersectoral actions contribute to have favorable results for children and women. Krulewitch \& Pierre-Louis M. L. [13] evaluated pregnant and non-pregnant women 
with respect to sociodemographic characteristics and the cause of death. The research identified that maternal deaths were visible but behind them were social factors that could be involved in pregnancy. According to Krulewitch \& Pierre-Louis M. L. [13] it is important to understand and have a clear definition of the risks of mortality during pregnancy, as well as to extend that same definition to further observe the associations associated with death; domestic problems are frequently associated with maternalperinatal morbidity and mortality. Regarding the results in the sociocultural aspects, we observed how the mixed backgrounds and white ethnic groups had a greater association with the maternal mortality ratio for the period 2000-2019. It was observed that there are studies such as those of Barreto RS [14], which indicated that the mixed backgrounds and white ethnic group was more prevalent in having causes of hypertensive disease, related to maternal death.

Regarding prenatal control, several studies from the World Health Organization (WHO) recommend prenatal care for a safe pregnancy, allowing evidence-based medicine to strengthen the care of women. These reviews allow you to create up-to-date guides with a practical and normative component. The activities that are derived from the guides and norms, lead the woman to have a projection on her pregnancy and a positive experience; among them we have the maintenance of her physical and sociocultural integrity, mother and child health, an effective transition from labor and birth, as well as positive motherhood (good self-esteem, competence, and autonomy). Our study was able to show that in the absence of prenatal control, the maternal mortality ratio increased by $24 \%$. Pazmiño S. \& Guzman N. [5] in the city of Cali argued that although there has been little variation in the coverage of prenatal care and institutional delivery and the conditions of social and economic development, the decrease in maternal mortality ratios must attribute to the efficiency and effectiveness of the programs the quality of prenatal care. The importance value of encouraging prenatal controls is that it complies with the five attributes: precociousness, periodicity, completeness, coverage, and gratuitousness; with the purpose of detecting and treating obstetric and perinatal morbidity, in addition to studying biological and biopsychosocial risks. Gómez-De la Rosa \& MarrugoArnedo C. A. [15], revealed that the group that attended prenatal controls reduced the value of the maternal mortality ratio from 166.6 to 72.7 per 100,000 live births. The reduction of illiteracy and the improvement of socioeconomic conditions are associated with the reduction of maternal mortality [6]-[8].

The techniques used for spatial analysis identified that there is a risk pattern linked to sociodemographic characteristics [2], [16]. Although high risks were not evidenced, a combination of low-low-high-low conglomerates could be observed in specific areas of the north and center of the municipality of Santiago de CaliColombia (Fig. 3). With the clusters, it was also possible to observe that it is to be expected that the socioeconomic strata involved in low-low and high-low risk factors were not at a disadvantage of poverty conditions or undermining women's health opportunities. Although the correlation study did not show clusters in the depressed areas of the city; simple georeferencing maps showed that maternal mortality is a high-frequency event and should be taken into account for the establishment of policies in these sectors, as reported in the literature [16]. The main difficulty in the search for the variables added in the years 2000-2019 at the municipal level was the achievement of variables since it was not properly recorded, they did not have a specific format without monitoring.

To our knowledge, the main strength of the study is having analyzed MM for twenty years with information from three different sources adequately systematized, complemented with information obtained from primary sources through interviews. Regarding public policy, according to the literature, it is necessary for decision makers in public policies to evaluate the role of women in society, pay attention to their economic income and workloads. Women should have the same rights as men to get a decent and well-paid job, and she can resolve her pregnancy status without any complications. With the aggravation that more than a third of pregnancies in Colombia are unwanted and occur in a high proportion in unmarried women [6], [10], [15]. Education is fundamental in the recognition of women's rights; it helps them to make decisions in the pregnancy process and to easily recognize risk factors. Although both ethnic groups and hispanic were vulnerable in this study, it was evidenced that it is necessary to carry out strategies to avoid inequality, strengthen universal rights for medical care and protection of pregnant women [12], [17].

According to the World Health Organization (WHO), around 830 women die every day from preventable causes related to pregnancy, childbirth, and the puerperium. It is a sustainable development objective (SDG) to reduce maternal mortality by three-quarters compared to those presented in 1990 , with a minimum coverage of $85 \%$ in prenatal control and institutional delivery care. In Latin America the figures have decreased (with regional differences); however, in Africa and Asia they continue to be high, possibly due to social determinants [18], which would be desirable to be explored in future studies in these countries, evaluating socio-economic variables that allow a better dimension of the problem in a comprehensive way, in order to that decision makers in public policy may have more elements that allow better focus interventions for the population. Future studies are needed to evaluate not only individual but collective variables to determine risks attributable to the population.

\section{CONFLICT OF INTEREST}

None to be declared.

\section{REFERENCES}

[1] Hazarika L, Phukan P, Sharma A, Kr. Das N. Maternal mortality at a tertiary care teaching hospital in Dibrugarh district, Assam: a retrospective study. Int J Community Med Public Health. 2017 Aug $23 ; 4: 3342$ 
[2] Kirby RS, Delmelle E, Eberth JM. Advances in spatial epidemiology and geographic information systems. Annals of Epidemiology. 2017 Jan;27(1):1-9.

[3] Hosmer DW Jr, Lemeshow S, Sturdivant RX. Application of Logistic Regression with Different Sampling Models. In: Applied Logistic Regression [Internet]. John Wiley \& Sons, Inc.; 2013. p. 227-242. Available from: http://dx.doi.org/10.1002/9781118548387.ch6.

[4] VanderWeele, T. J., Tchetgen Tchetgen, E. J. (2014). Attributing Effects to Interactions. Epidemiology, 25(5), 711-722.

[5] Pazmiño de Osorio - Guzman N. Control prenatal y su impacto en la Mortalidad Materna. Rev. Colomb. Obstet Ginecol 2009; 60(1): 12-8.

[6] Salazar E, Buitrago C, Molina F, Arango C. Tendencia de la mortalidad por causas externas en mujeres gestantes o puerperas y su relación con factores socio-económicos en Colombia. 1998-2010. Rev Panam Salud Publica 2011; 37(4/5): 225-231.

[7] Liese KL, Maeder AB. Safer Muslim motherhood: Social conditions and maternal mortality in the Muslim world. Glob Public Health. 2017 Sep 20; 1-15.

[8] Feng X, Zhu J, Zhang L, Song L, Hipgrave D, Guo S, et al. Socioeconomic disparities in maternal mortality in China between 1996 and 2006. BJOG 2010;117(12):1527-36.

[9] Bobby HA. Social status, and men immune response: a meta-analysis. Philos Trans R Soc Lond B Biol Sci. 2015; 370: 1669.

[10] Cárdenas-Cárdenas LM, Cotes-Cantillo K, Chaparro-Narváez PE, Fernánde Niño JA, Paternina-Caicedo A, Castañeda-Orjuela C, et al. Maternal mortality in Colombia in 2011: A two level ecological study. PLOS ONE [Internet]. 2015 Mar 18 [cited 2015 Sep 7];10(3). Available

from: http://www.ncbi.nlm.nih.gov/pmc/articles/PMC4364963.

[11] ASIS 24022014.PDF [Internet]. [cited 2015 Sep 7]. Available from: https://www.minsalud.gov.co/sites/rid/Lists/BibliotecaDigital/RIDE/ VS/ED/PSP/ASIS\%2024022014.pdf.

[12] Pina M de F de, Alves SF, Ribeiro AIC, Olhero AC. Epidemiología espacial: nuevos enfoques para viejas preguntas [Internet]. Universitas Odontológica. 2010 [cited Sep 7 2015]. Available from: http://www.redalyc.org/articulo.oa.id=231216366007.

[13] Krulewitch CJ, Pierre-Louis ML, de Leon-Gomez R, Guy R, Green R. Hidden from view: violent deaths among pregnant women in the district of columbia, 1988-1996. J Midwifery Women's Health. 2001;46(1):4-10.

[14] Barreto Rivero S. Preeclampsia severa, eclampsia y sindrome de HELLP: caracteristicas maternas y resultado neonatal. Unidad de Cuidados Intensivos Maternos. Instituto Materno Perinatal. Lima, Perú 1999-2000. Rev Hosp Materno Infant Ramon Sarda [Internet]. 2002 [cited 2017 Sep 25]; 21(1).

[15] Gomez de la Rosa F, Marrugo-Arnedo CA, Florez-Tanus A, LopezPajaro K, Mazenett-Granados M, Orozco-Africano J et al. Impacto económico y sanitario del control prenatal en embarazadas afiliadas al régimen subsidiado en Colombia durante 2014. Salud Publica Mex 2017; 59:176-82.

[16] Rodrigues NCP, Monteiro DLM, Almeida AS de, Barros MB de L, Pereira Neto A, O'Dwyer G, et al. Temporal and spatial evolution of maternal and neonatal mortality rates in Brazil, 1997-2012. J Pediatr (Rio J) 2016;92(6):567-73.

[17] Tucker MJ, Berg CJ, Callaghan WM, Hsia J. The black-white disparity in pregnancy-related mortality from five conditions: differences in prevalence and case-fatality rates. Am J Public Health. 2007;97(2):247-251. 